\title{
Pengaruh Penguasaan Kalimat Efektif dan Kosakata terhadap Keterampilan Berbicara
}

\author{
Dyah Utami ${ }^{1)}$ \\ Suparman Ibrahim Abdullah ${ }^{2)}$ \\ Fakultas Pascasarjana, Universitas Indraprasta PGRI \\ Jalan Nangka No. 58 C/TB. Simatupang, Tanjung Barat, \\ Jakarta Selatan 12530
}

\begin{abstract}
This reaserch aims to analyze the effect simultaneously and partially of mastery of effective sentences and vocabulary mastery of speaking skills, especially junior high school students in Tangerang City. If indeed there is a positive and significant influence then how strong the influence of effective sentence mastery and vocabulary mastery of speaking skills. The research method used is a survey with correlation and regression analysis, that is by connecting data showing the mastery of effective sentences and mastery of vocabulary with data showing the writing skills of students in the speech in which case the form is in speech. Data on the variable of effective sentence mastery and vocabulary mastery variable is obtained through a direct written test of the respondent. The test is performed using multiple choice questions. Data on speech skills are obtained through a direct test by asking respondents to make a speech whose theme is determined by the researcher. From the result of data analysis of research, it can be concluded that: (1) there is a significant influence of effective vocabulary mastery and vocabulary on speaking skill of SMP Negeri student in Tangerang City, this is proved by Sig = $0,000<0,05$ and Fhitung $=38,868$; (2) there is a significant influence of effective sentence mastery of speaking skills at the State students in Tangerang City, this is evidenced by the value of Sig $=0.004$ and count $=2.992$; and (3) there is significant influence of vocabulary mastery of speaking skill at State student in Tangerang City, this is proved by Sig $=0.000$ and count $=$ 4,328 .
\end{abstract}

Keywords: mastery of effective sentences, vocabulary mastery, speaking skills

\begin{abstract}
Abstrak
Penelitian ini bertujuan untuk menganalisis pengaruh secara simultan dan parsial dari penguasaan kalimat efektif dan penguasaan kosakata keterampilan berbicara, khususnya siswa SMP di Kota Tangerang. Jika memang ada pengaruh positif dan signifikan maka seberapa kuat pengaruh penguasaan kalimat efektif dan penguasaan kosakata keterampilan berbicara. Metode penelitian yang digunakan adalah survei dengan analisis korelasi dan regresi, yaitu dengan menghubungkan data yang menunjukkan penguasaan kalimat yang efektif dan penguasaan kosakata dengan data yang menunjukkan keterampilan menulis siswa dalam pidato yang dalam hal ini bentuknya dalam pidato. Data tentang variabel penguasaan kalimat efektif dan variabel penguasaan kosakata diperoleh melalui tes tertulis langsung dari responden. Tes ini dilakukan menggunakan beberapa pertanyaan pilihan. Data tentang keterampilan berbicara diperoleh melalui tes langsung dengan meminta responden untuk membuat pidato yang temanya ditentukan oleh peneliti. Dari hasil analisis data penelitian, dapat disimpulkan bahwa: (1) ada pengaruh yang signifikan penguasaan kosakata efektif dan kosakata terhadap keterampilan berbicara siswa SMP Negeri di Kota Tangerang, hal ini dibuktikan oleh Sig = 0,000<0, 05 dan Fhitung = 38.868; (2) ada pengaruh signifikan penguasaan kalimat efektif keterampilan berbicara pada siswa di Kota Tangerang, ini dibuktikan dengan nilai Sig $=0,004$ dan hitung $=2,992$; dan (3) ada pengaruh yang signifikan penguasaan kosakata keterampilan berbicara pada siswa negeri di Kota Tangerang, hal ini dibuktikan oleh Sig = 0,000 dan hitung =4,328.
\end{abstract}

Kata kunci: penguasaan kalimat yang efektif, penguasaan kosakata, keterampilan berbicara 


\section{PENDAHULUAN}

Bahasa Indonesia merupakan salah satu mata pelajaran yang dianggap penting dalam dunia pendidikan di Indonesia sebab bahasa Indonesia merupakan bahasa nasional dan bahasa persatuan. Mata pelajaran ini dipelajari mulai dari jenjang pendidikan dasar hingga perguruan tinggi, begitu pentingnnya penggunaan bahasa Indonesia sehingga menjadi perhatian para pendidik. Bahasa Indonesia mencakup keterampilan berbahasa (menyimak, berbicara, membaca, menulis) semua keterampilan tersebut saling mempengaruhi satu dengan lain. Pada hakikatnya belajar bahasa adalah belajar berkomunikasi. Untuk itulah pengajaran Bahasa dan Sastra Indonesia bertujuan agar siswa dapat menggunakan bahasa Indonesia dengan baik dan benar dalam berbagai keperluan dan meningkatkan kemampuan penalaran serta kematangan emosional dan sosial.

Ruang lingkup mata pelajaran Bahasa Indonesia di Sekolah Menengah Pertama mencakup komponen kemampuan atau kompetensi dalam berbahasa dan kemampuan dalam bersusastra. Secara garis besar, kompetensi tersebut dijabarkan menjadi: (1) kompetensi mendengarkan (menyimak), (2) kompetensi berbicara, (3) kompetensi membaca. dan (4) kompetensi menulis.Salah satu aspek kemampuan berbahasa yang sangat penting peranannya dalam upaya melahirkan generasi muda masa depan yang cerdas, kritis, kreatif, dan berbudaya adalah melalui keterampilan berbicara.

Keterampilan berbicara merupakan salah satu keterampilan berbahasa yang dianggap sebagai alat kontrol sosial bagi manusia. Tarigan (2003 : 15) mengatakan bahwa "berbicara merupakan suatu bentuk perilaku manusia yang memanfaatkan faktor-faktor fisik, psikologis, neorologis, semantis dan linguistik yang sangat intensif." Namun demikian, tanpa mengabaikan keterampilan berbahasa yang lainnya, keterampilan berbicara memang dipandang memiliki peranan sentral dalam tujuan pembelajaran bahasa, karena hakekat belajar bahasa adalah belajar komunikasi, terutama komunikasi lisan atau verbal. Demikian pula dengan hakikat pembelajaran bahasa Indonesia.

Hakikat pembelajaran bahasa Indonesia ialah peningkatan kemampuan siswa untuk berkomunikasi dalam bahasa Indonesia yang baik dan benar secara lisan dan tulisan. Keterampilan berbicara juga sering dipandang sebagai tolak ukur utama untuk menilai keberhasilan dalam pembelajaran bahasa. Dengan menguasai keterampilan berbicara, peserta didik akan mampu mengekspresikan pikiran dan perasaannya secara cerdas sesuai konteks dan situasi pada saat dia sedang melakukan aktivitas berbicara. Keterampilan berbicara juga akan mampu membentuk generasi muda masa depan yang kreatif sehingga mampu melahirkan tuturan atau ujaran yang komunikatif, jelas, runtut, dan mudah dipahami oleh lawan bicaranya.

Ditegaskan lebih lanjut, esensi bahasa pada dasarnya adalah berbicara (berkomunikasi). Bahasa pada masa ini merupakan sesuatu yang dianggap penting keberadaan serta peranannya. Bahasa merupakan alat komunikasi yang bisa dinikmati oleh semua makhluk di belahan bumi manapun, karena dengan bahasa, kita akan mengetahui berbagai macam informasi.Keraf, (2007 : 42) mengatakan bahwa "semua aktivitas manusia yang terencana didasarkan pada bahasa. Bahasa 
sendiri mempunyai bentuk dasar berupa ucapan atau lisan." Jadi jelas bahwa belajar bahasa pada hakikatnya adalah belajar komunikasi, dan komunikasi itu adalah berbicara.

Pada hakikatnya, siswa telah menyadari bahwa keterampilan berbicara merupakan sarana untuk berkomunikasi, atau bekal melanjutkan studi ke jenjang yang lebih tinggi. Namun perlu diketahui bahwa setiap mendapat tugas berbicara siswa seringkali mengalami kesulitan. Kesulitan tersebut dapat berupa kesulitan dalam pemilihan kosa kata yang tepat, kurang lancar berbicara, maupun kurang jelas dalam pengungkapan gagasannya. Dan bila ini terjadi tentulah sangat mempengaruhi keefektivitasan dalam berbicara.

Seperti yang disinggung oleh Halim (2004: 67) bahwa "beberapa faktor yang mempengaruhi kefektifan dalam berbicara adalah; lafal atau ucapan dan pola-pola intonasi serta tekanan, penguasaan tata Bahasa, penguasaan struktur kalimat, penguasaan kelancaran, kefasihan dan pemahaman kosakata." Faktorfaktor tersebut menjadikan sangat efektif apabila pembicara juga memperhatikan hal-hal yang bersifat kebahasaan maupun non kebahasaan.

Di sini penulis akan menggarisbawahi bahwa kemampuan menyusun kalimat efektif sebagai salah satu faktor yang cukup berpengaruh dan merupakan salah satu unsur bahasa yang memegang peranan penting dalam aktivitas berbicara. Melalui penguasaan kalimat efektif yang tinggi, kita dapat mengekspresikan pikiran, gagasan, serta perasaan kita kepada orang lain dengan baik. Hal ini dikarenakan kalimat merupakan sarana komunikasi untuk menyampaikan pikiran ataugagasan kepada orang lain agar dapat dipahami dengan mudah. Komunikasiberlangsung baik dan benar jika menggunakan kalimat yang baik dan benar,yaitu kalimat yang dapat mengekspresikan gagasan melalui ucapan/bicara secara jelas dan tidakmenimbulkan keraguan bagi pendengarnya. Untuk itu, kalimat harusdisusun berdasarkan struktur yang benar, sehingga pengugkapan gagasan tersebut bisa dilakukan secarabaik, yaitu singkat, cermat, tepat, jelas maknanya, dan santun.

Berdasarkan pengamatan penulis di lingkungan siswa yang ada di sekolah tempat punulis bertugas, penguasaan kalimat efektif yang dimiliki oleh siswa masihsangat kurang. Ketika mereka diminta untuk berpidato atau bentuk tutur lisan yang lain, masih sering ditemukan beberapa struktur kalimat yang tidak benar. Tidak jelas mana subjeknya, dan mana predikatnya. Bahkan masih banyak pula penggunaan dan pemilihan kosakata (diksi) yang tidak tepat, tidak baku. Kesalahan dalam penggunaan ejaan dan penerapan tanda baca pun juga masih sering ditemukan. lni dibuktikan dengan masih banyaknya hasil karya tulis siswa dengan penggunaan kosakata yang kurang tepat, kurang kreatif, dan sulit dipahami karena penguasaan struktur kalimat yang kurang efektif serta pemilihan teknik pengembangan paragraf yang salah.

Kalimat efektif sangat berhubungan erat dengan berbicara, jika siswa tidak mampu menguasai kalimat efektif, maka narasi yang ditulis akan sulit dimengerti oleh pembaca. Kalimat efektif adalah kalimat yang dapat mewakili gagasan pembicara atau penulis serta dapat diterima maksudnya/arti serta tujuannya seperti yang di maksud penulis. Syafi'ie (2003: 8)berpendapat bahwa kalimat efektif adalah kalimat yang mampu membuat isi atau maksud yang disampaikan itu 
tergambar lengkap dalam pikiran penerima (pembaca) persis seperti apa yang disampaikan.

Faktor yang lain yang diduga mempengaruhi kesulitan siswa untuk berkomunikasi dalam bahasa Indonesia terutama adalah kurangnya perbendaharaan kata/kosakata yang akan digunakan untuk berkomunikasi.

Dalam berbicara penguasaan kosakata memegang peranan penting karena dengan penguasaan kosakata yang baik kegiatan komunikasi dengan orang lain akan terjalin dengan baik. Keterampilan berbicara tidak akan dapat di wujudkan tanpa adanya penguasaan kosakata terlebih dahulu. Kosakata adalah perbendaharaan kata yaitu kata-kata yang dipahami orang baik maknanya maupun penggunaannya.Henry Guntur Tarigan (2003 : 2) berpendapat bahwa "kualitas keterampilan berbahasa seseorang jelas bergantung kepada kuantitas dan kualitas kosakata yang dimilikinya."

Mengacu beberapa perkiraan-perkiraan jawaban di atas, penulis tertarik untuk mengadakan penelitian kembali, yang tentunya kali ini lebih mendalam di SMP Negeri di kota Tangerang, guna menguji ada tidaknya hubungan signifikan antara kemampuan membacadan penguasaan kosakata mereka dengan keterampilan berbicara yang dihasilkan.

Berdasarkan latar belakang tersebut penulis tertarik untuk melakuan penelitian yang bertemapengaruh penguasaan kalimat efektif dan penguasaan kosakataterhadap keterampilan siswa dalam berbicara, khususnya bagi siswa SMP Negeri di wilayah kota Tangerang.

\section{METODE}

Penelitian ini termasuk dalam jenis penelitian eksplanatari dengan pendekatan kuantitatif, dan teknik analisis data serta pengujian hipotesisnya dengan menggunakan teknik analisi korelasi dan regresi sederhana tunggal dan berganda. Populasi penelitian ini adalah siswa kelas VIII SMP Negeri diKota Tangerang tahun pelajaran 2017/2018 yang dibatasi pada siswakelas VIII SMP Negeri 3 Kota Tangerang, SMP Negeri 11 Kota Tangerang, dan SMP Negeri 24 Kota Tangerang tahun pelajaran 2017/2018. Jumlah anggota sampel ditentukan dengan menggunakan rumus Slovin sehingga diperoleh sampel dengan anggota sebanyak 60 orang siswa. Untuk teknik pemilihan sampel digunakan gabungan dari teknik cluster, proporsional, dan acak.

Instrumen ini berupa tes sebanyak 30 butir soal berbentuk pilihan ganda dengan 4 pilihan jawaban yang dikembangkan dari indikator-indikator : (1) ejaan dan kata baku, yaitu kemampuan menggunakan ejaan maupun kata atau istilah yang baku sesuai kaidah tata bahasa; (2) kelogisan, yaitu kemampuan menyusun kalimat yang logis dan maksudnya mudah dipahami; (3) ringkas atau hemat, yaitu kemampuan menyusun kalimat yang tidak berbelit-belit; (4) kohesi dan koherensi, yaitu kemampuan menulis kalimat yang mempunyai struktur yang sepadan dan padu; dan (5) variasi bahasa, kemampuan menggunakan pilihan kata yang bervariasi.

Instrumen ini berupa tes sebanyak 30 butir soal berbentuk pilihan ganda dengan 4 pilihan jawaban yang dikembangkan dari indikator-indikator : (1) 
Diskursus: Jurnal Pendidikan Bahasa Indonesia

Vol. 1, No. 1, April 2018, pp. 30-38

p-ISSN: 2615-4935

e-ISSN: 2615-4943

Penguasaan perbendaharaan kata; (2) Penguasaan terhadap padan kata; dan (3) Pemahaman terhadap kata-kata ungkapan.

Keterampilan berbicaradiukur melalui penuturan responden dalam berpidato berdasarkan tema/topik/judul yang diberikan oleh peneliti. Adapun kriteria penilaian pidato tersebut adalah :

Tabel 1. Kriteria Penilaian Berbicara (Pidato)

\begin{tabular}{clc}
\hline No & \multicolumn{1}{c}{ Indikator Penilaian } & Kriteria Penilaian \\
\hline 1 & Vokal & $1-20$ \\
2 & Tema & $1-10$ \\
3 & Penguasaan Materi & $1-15$ \\
4 & Komunikasi & $1-15$ \\
5 & Gaya Bahasa & $1-10$ \\
6 & Penampilan & $1-15$ \\
7 & Ekspresi & $1-15$ \\
& Jumlah Skor & $\mathbf{7 - 1 0 0}$ \\
\hline
\end{tabular}

\section{HASIL DAN PEMBAHASAN}

Hasil

Analisis data baik yang terkait dengan penyajian data, pengujian persyaratan data, maupun yang terkaitdengan pengujian hipotesis dilakukan dengan bantuan program aplikasi SPSS versi 24. Hasil-hasil yang terkait dengan pengujian hipotesis adalah berikut :

Tabel 2. Hasil Perhitungan Koefisien Korelasi Berganda Pengaruh Variabel $X_{1}, X_{2}$, dan $X_{3}$ terhadap Variabel $Y$

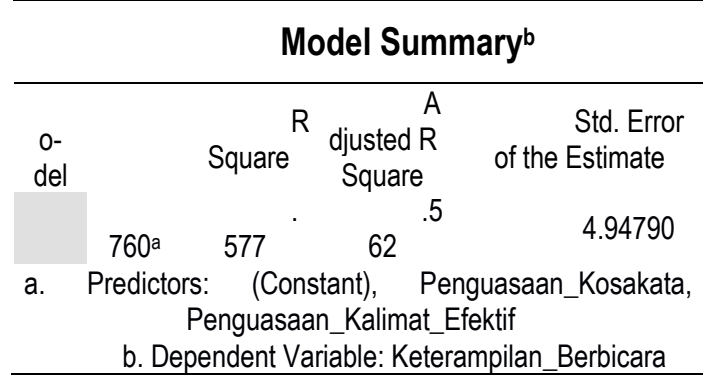

Tabel 3. Hasil Perhitungan Persamaan Garis Regresi Berganda dan Analisis Pengaruh Partial Variabel $X_{1}, X_{2}$, dan $X_{3}$ terhadap Variabel $Y$ Coefficients $^{a}$

\begin{tabular}{|c|c|c|c|}
\hline Model & $\begin{array}{l}\text { Unstand } \\
\text { ardized } \\
\text { Coefficients }\end{array}$ & $\begin{array}{c}\text { tan } \\
\text { dar } \\
\text { dize } \\
\text { d } \\
\text { Coe } \\
\text { ffici } \\
\text { ents }\end{array}$ & ig. \\
\hline
\end{tabular}


Diskursus: Jurnal Pendidikan Bahasa Indonesia

Vol. 1, No. 1, April 2018, pp. 30-38

p-ISSN: $2615-4935$

e-ISSN: 2615-4943

\begin{tabular}{|c|c|c|c|c|c|}
\hline \multicolumn{6}{|c|}{ Std } \\
\hline & & Error & eta & & \\
\hline \multirow[b]{2}{*}{ nstant) } & & & & & \\
\hline & 5.935 & 599 & & & 000 \\
\hline $\begin{array}{l}\text { Pen } \\
\end{array}$ & & & 340 & & \\
\hline imat_Efektif & 236 & 19 & & .992 & 004 \\
\hline $\begin{array}{l}\text { Pen } \\
\text { guasaan_Ko } \\
\text { sakata }\end{array}$ & 294 & 68 & .492 & .328 & 000 \\
\hline
\end{tabular}

Tabel 4. Rekapitulasi Hasil Perhitungan Pengujian Signifikasi Koefisien Regresi Pengaruh Simultan Variabel $X_{1}, X_{2}$, dan $X_{3}$ terhadap Variabel $Y$

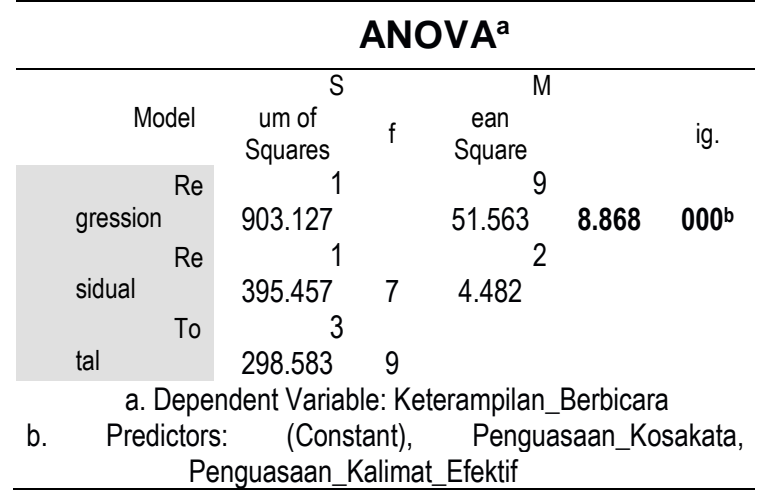

\section{Pengaruh Penguasaan Kalimat Efektif dan Kosakata secara Bersama-sama terhadap Keterampilan Berbicara}

Dari analisis korelasi diperoleh koefisien korelasi berganda pengaruh variabel bebas penguasaan kalimat efektif $\left(\mathrm{X}_{1}\right)$ dan penguasaan kosakata $\left(\mathrm{X}_{2}\right)$ secara bersama-sama terhadap keterampilan berbicara $(\mathrm{Y})$ adalah sebesar 0,76 . Dari hasil pengujian diperoleh bahwa koefisien korelasi tersebut signifikan, dengan kata lain bahwa terdapat pengaruh yang signifikan variabel bebas penguasaan kalimat efektif $\left(\mathrm{X}_{1}\right)$ dan penguasaan kosakata $\left(\mathrm{X}_{2}\right)$ secara bersamasama terhadap keterampilan berbicara (Y). Sedangkan koefisien determinasinya adalah sebesar $57,7 \%$ menunjukkan bahwa besarnya kontribusi penguasaan kalimat efektif dan kosakata secara bersama-sama terhadap keterampilan berbicara adalah sebesar $57,7 \%$, sisanya $(42,3 \%)$ karena pengaruh faktor lain yang tidak diteliti.

Untuk pengujian hipotesis melalui analisis regresi diperoleh hasil perhitungan terlihat pada Tabel 3. dan Tabel 4, Dari Tabel 3. diperoleh persamaan garis regresi yang merepresentasikan pengaruh variabel $\mathrm{X}_{1}$ dan $\mathrm{X}_{2}$ terdahap variabel $\mathrm{Y}$, yaitu $\widehat{\mathbf{Y}}=35,935+0,236 \mathrm{X}_{1}+0,294 \mathrm{X}_{2}$. Nilai konstanta = 35,935menunjukkan bahwa dengan penguasaan kalimat efektif dan penguasaan kosakata siswa paling rendah sulit bagi siswa tersebut untuk bisa meraih pretasi belajar yang baik, sedangkan nilai koefisien regresi sebesar 0,236dan 0,294menunjukkan bahwa terdapat pengaruh positif variabel bebas $X_{1}$ 
(penguasaan kalimat efektif) dan $\mathrm{X}_{2}$ (penguasaan kosakata) secara bersama-sama terhadap variabel terikat $\mathrm{Y}$ (keterampilan berbicara). Angka koefisien regresi tersebut juga menunjukkan bahwa setiap ada kenaikan satu nilai pada variabel penguasaan kalimat efektif maka akan terdapat kenaikan pada variabel keterampilan berbicara sebesar 0,236, dan setiap ada kenaikan satu nilai pada variabel penguasaan kosakata siswa maka akan terdapat kenaikan pada variabel keterampilan berbicara sebesar 0,294 satuan.

Setelah dilakukan pengujian, diperoleh bahwa nilai Sig $=0.000<0,05$ dan $\mathbf{F}_{\text {hitung }}=38,868$, maka $\mathrm{H}_{0}$ ditolak dan $\mathrm{H}_{1}$ diterimayang berarti bahwa regresi tersebut signifikan. Hal itu menunjukkan bahwa memang terdapat pengaruh yang signifikan variabel bebas penguasaan kalimat efektif $\left(\mathrm{X}_{1}\right)$ dan penguasaan kosakata $\left(\mathrm{X}_{2}\right)$ secara bersama-sama terhadap keterampilan berbicara $(\mathrm{Y})$.

\section{Pengaruh Penguasaan Kalimat Efektif terhadap Keterampilan Berbicara}

Dari tabel Coefficients ${ }^{\mathrm{a}}$ di atas, pada baris Penguasaan_Kalimat_Efektif

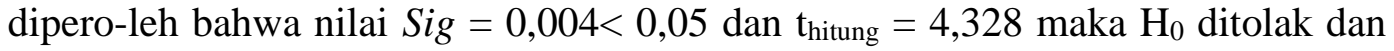
$\mathrm{H}_{1}$ diterima yang berarti terdapat pengaruh yang signifikan penguasaan kalimat efektif terhadap keterampilan berbicara.

\section{Pengaruh Penguasaan Kosakata terhadap keterampilan Berbicara}

Dari tabel Coefficients ${ }^{\mathrm{a}}$ di atas, pada baris Sikap_Pada_Matematikadiperoleh bahwa nilai Sig $=0,000<0,05$ dant $_{\text {hitung }}=3,928$ maka $\mathrm{H}_{0}$ ditolak dan $\mathrm{H}_{1}$ diterima yang berarti terdapat pengaruh yang signifikan penguasaan kosakata terhadap keterampilan berbicara.

\section{SIMPULAN}

Berdasarkan deskripsi data penelitian dan setelah dikalukan analisis maka dapat disimpulkan: 1. Terdapat pengaruh yang signifikan penguasaan kalimat efektif dan kosakata secara bersama-sama terhadapketerampilan berbicara pada siswa SMP Negeri di Kota Tangerang. Hal ini dibuktikan olehnilai Sig $=0,000<$ 0,05 dan $F_{\text {hitung }}=38,868$. 2. Terdapat pengaruh yang signifikan penguasaan kalimat efektif terhadapketerampilan berbicara pada siswa Negeri di Kota Tangerang.Hal ini dibuktikan oleh nilai $\mathrm{Sig}=0,004<0,05$ dan $t_{\text {hitung }}=2,992$. 3 . Terdapat pengaruh yang signifikan penguasaan kosakata terhadapketerampilan berbicara pada siswa Negeri di Kota Tangerang.Hal ini dibuktikan oleh nilai Sig = $0.000<0,05$ dan thitung $=4,328$.

Saran yang dapat disampaikan adalah sebagai berikut: 1. Guru Bahasa Indonesia agar selalu melakukan pembinaan kepada siswa/siswinya dalam hal meningkatkan penguasaan kalimat efektif, karena penguasaan kalimat efektif memang sangat penting dan akan selalu berguna meningkatkan keterampilan berbicara. 2. Hendaknya para guru Bahasa Indonesia senantiasa melakukan pembinaan kepada siswa/siswinya dalam hal meningkatkan penguasaan kosakata, karena penguasaan kosakata memang sangat penting dan akan selalu berguna meningkatkan keterampilan berbicara. 3. Para orang tua hendaknya selalu memperhatikan perkembangan pendidikan kepada putra/putrinya. Perhatian 
tersebut tidak hanya sekedar mencukupi kebutuhan pendidikan putra/putrinya secara materi saja, tetapi juga bisa membantu putra/putrinya dalam menyelesaikan kesulitan-kesulitan dalam belajarnya. 4. Hendaknya para guru dan para pengelola lembaga pendidikan bisa memadukan antara penguasaan kalimat efektif dan penguasaan kosakata dari para siswanya untuk meningkatkan prestasi belajar pelajaran bahasa Indonesia khususnya keterampilan berbicara.

\section{DAFTAR PUSTAKA}

Abror, Abd. Rahman. 2004, Psiklogi Pendidikan. Yogyakarta : PT. Tiara Wacana Akhadiah, Sabarti. 2001. Pengantar Lingusitik. Yogyakarta: Gajah Mada University Press

Alwasilah. Chaedar., 2003. Tata Baku Bahasa Indonesia. Jakarta : Balai Pustaka Ardiana, Leo Indra., dkk.., 2002. Prinsip-prinsip Dasar Sastra. Bandung : Angkasa

Arifin, Zaenal dan S.Amran Tasai, 2005, Cermat Berbahasa Indonesia, Jakarta: CV Akamedika Pressindo

Djuherli dan Suherli. 2001. Telaah Wacana : Teori dan Penerapannya. Depok: Komodo Books

Dunnette, Garry., 2001. History of Educational Thought. New York: American Book Company

Gordon (et.al). 2004 Revolusi Cara Belajar (The Learning Revolution), Bandung: Kaifa

Hernowo. 2002. Memupuk Bakat dan Kreativitas Siswa Sekolah Menengah. Jakarta: Gramedia

Iverson, Thomas., 2001. Learning Principles and Application.Singapore : Mc Grow Hill.

Keraf, Gorys. 2007. Tata Bahasa Rujukan Bahasa Indonesia. Ende, Flores : Nusa Indah

Kosasih. E., 2008. Kumpulan Istilah dan Apresiasi Sastra Bahasa Indonesia. Surabaya : Pustaka Ilmu

Kridalaksana, Harimurti,, 2004, Kamus Linguistik, Jakarta, Gramedia Pustaka Utama

Marahimin . 2004., Panduan Belajar Bahasa dan Sastra Indonesia. Tangerang: Erlangga

Nadler, David., 2006. Fundamentals of Logic. New York: Mc. Grow-Hill Book Company

Nurgiyantoro, Burhan. 2001. Penilaian Pembelajaran Bahasa Berbasis Kompetensi. Yogyakarta : BPFE

Poerwadarminta. W.J.S. 1998, Kamus Umum Bahasa Indonesia, Jakarta: Balai Pustaka

Pranoto. Joni., 2004. Menulis Efektif. Bandung: Angkasa Raya

Robbins, S. P. 2003. Perilaku Organisasi. Jilid I. Jakarta: PT INDEKS Kelompok Garmedia 
Diskursus: Jurnal Pendidikan Bahasa Indonesia

Vol. 1, No. 1, April 2018, pp. 30-38

p-ISSN: 2615-4935

e-ISSN: 2615-4943

Rozak, Abdul., 2000. Kalimat Efektif: Diksi, Struktur, dan Logika. Bandung: Rafika Aditama

Rusyana. 2008. Keterampilan Dasar Menulis. Jakarta: Universitas Terbuk

Sabariyanto. Dirgo., 2001. Pembinaan Kemampuan Menulis Bahasa Indonesia. Jakarta:Erlangga

Semi, Atar. 2003. Menulis Efektif. Padang: Angkasa Raya

Sudiana. 2007. Bahasa \& Sastra Indone-sia SMA Kelas X. Surakarta: Yudhistira

Sudjiman. 2004. Terampil Menulis Paragraf. Jakarta: PT Grasindo

Suhendar. 2002. Prinsip - prinsip Dasar Sastra. Bandung : Angkasa

Tabrani, R. A. dkk, (2011). Pendekatan dalam proses belajar mengajar, Rosda Karya, Bandung

Tarigan, Henry Guntur, 2004. Pengajaran Kosakata.Bandung : Angkasa

Wijaya, Cece., Tabrani Rusyan. 2008. Kemampuan Dasar Guru dalam Proses Belajar Mengajar. Bandung: Remaja Rosdakarya

Zuchdi, Darmiyati. 2007. Metode Pengajaran Bahasa.Bandung : Angkasa 2008. Kemampuan Menulis dan Berbicara Akademik. Bandung : Rizqi Press 